\title{
A Comparison of Allograft Survival Between Cyclosporine and Tacrolimus Based Immunosuppressive Therapy in Kidney Transplantation: BIRDEM General Hospital Experience
}

\author{
Mitra $\mathrm{P}^{\mathrm{a}}$, Rahman MA ${ }^{\mathrm{b}}$, Rahim MA ${ }^{\mathrm{c}}$, Samdani TS ${ }^{\mathrm{d}}$, Sumon $\mathrm{AS}^{\mathrm{e}}$, Akhtar $\mathrm{M}^{\mathrm{e}}$, Kabir $\mathrm{MH}^{\mathrm{e}}$, Haque \\ $\mathrm{MS}^{\mathrm{e}}$, Pappu MHI ${ }^{\mathrm{e}}$, Billah $\mathrm{MM}^{\mathrm{f}}$, Chowdhury TA ${ }^{\mathrm{f}}$, Ananna MAc ${ }^{\mathrm{c}}$, Haque WMMㅁ, Iqbal Sg, \\ Mansur MA ${ }^{\text {h }}$
}

\begin{abstract}
Introduction and Aims: Calcineurin inhibitors (CNIs), cyclosporine and tacrolimus, are one of the three major components of basic immunosuppressive therapy of kidney transplantation. Our aims were to study and compare the early and long-term graft survival in kidney transplant recipients who were receiving either of these two CNIs.

Methods: A questionnaire was formed and data were collected from the hospital records. We divided the patients in group 1 (patients on cyclosporine) and group 2 (patients on tacrolimus). We retrospectively evaluated patients' clinical and laboratory findings.

Results: Group 1 included 50 patients who were on cyclosporine and group 2 included 61 patients who were on tacrolimus. Patients receiving tacrolimus showed almost similar renal function as cyclosporine receiving patients; serum creatinine was $1.27 \pm 0.56$ versus $1.42 \pm 0.91 \mathrm{mg} / \mathrm{dL}$ ( $p=0.258)$, but they required less time for serum creatinine to become normal ( $4.71 \pm 2.3$ versus $7.26 \pm 5.6$ days, $p=0.001)$ and less duration of post-transplant hospital stay $(11.38 \pm 3.33$ versus $13.65 \pm 5.0$ days, $p=0.005)$. New onset diabetes was more pronounced in group 2 (29.5\% versus $12 \%, p=0.025)$. On the other hand, acute rejection was only noted in group 1 (2 versus $0, p=0.014)$. One-year and three-year graft survival for cyclosporine was $92.0 \%$ and 83.3\%, and for tacrolimus was $96.2 \%$ and $89.2 \%$ respectively.
\end{abstract}

Conclusions: Tacrolimus is relatively favourable to cyclosporine in preventing acute allograft rejection and better immediate post-transplant graft function recovery.

Key words: Cyclosporine; graft survival; kidney transplantation; tacrolimus.

(Birdem Med J 2015; 5(2): 78-81.)

a. Dr. Palash Mitra, MBBS, Assistant Registrar, Nephrology and Dialysis, BIRDEM General Hospital, Dhaka, Bangladesh.

b. Dr. Md. Anisur Rahman, MD (Nephrology), Junior Consultant, Nephrology and Dialysis, BIRDEM General Hospital, Dhaka, Bangladesh.

c. Dr. Muhammad Abdur Rahim, FCPS (Medicine); Dr. Mehruba Alam Ananna, FCPS (Medicine), Assistant Professor, Nephrology and Dialysis, BIRDEM General Hospital, Dhaka, Bangladesh.

d. Dr. Tasrina Shamnaz Samdani, MBBS, Medical Officer, Coronary Care Unit, BIRDEM General Hospital, Dhaka, Bangladesh.

e. $\quad$ Ahmed Sharif Sumon, MBBS; Dr. Moontasim Akhtar, MBBS; Dr. Md. Hasanul Kabir, MBBS; Mirza Shariful Haque, MBBS; Dr. Md. Hedayetul Islam Pappu, MBBS; Senior Medical Officer, Nephrology and Dialysis, BIRDEM General Hospital, Dhaka, Bangladesh.

f. Dr. Md. Mostarshid Billah, FCPS (Medicine); Dr. Tufayel Ahmed Chowdhury, FCPS (Medicine); Registrar, Nephrology and Dialysis, BIRDEM General Hospital, Dhaka, Bangladesh.

g. Dr. Wasim Md. Mohosinul Haque, FCPS (Medicine); Sarwar Iqbal, MD (Nephrology); Associate Professor, Nephrology and Dialysis, BIRDEM General Hospital, Dhaka, Bangladesh.

h. Dr. Md. Abul Mansur, Dip (Nephrology), Professor, Nephrology and Dialysis; Director, Transplant Unit, BIRDEM General Hospital, Dhaka, Bangladesh.

Address of correspondence: Dr. Palash Mitra, MBBS, Assistant Registrar, Nephrology and Dialysis, BIRDEM General Hospital, Dhaka, Bangladesh, Email: palash_mtr@yahoo.com

Received: January 13, 2014

Accepted: June 30, 2015 


\section{Introduction}

Kidney transplantation is the optimum treatment for most patients with end-stage renal disease. Immunosuppression remains the cornerstone of solid organ transplantation to prevent graft failure and increase graft survival. Basic maintenance immunosuppression for many years consisted of three types of drugs in combination: glucocorticosteroid (prednisolon), a purine antagonist (azathioprine or mycophenolate mofetil) and a calcineurin inhibitor (CNI, for example, cyclosporine or tacrolimus). ${ }^{1-3}$

In 1983, FDA approved cyclosporine for mass use. Since then the new era of solid organ transplant begins. ${ }^{4}$ Much of the success in organ transplantation has been credited to the use of cyclosporine. After its introduction, renal graft survival at 1 year increased from $64 \%$ to $78 \% .{ }^{5}$ But, despite the improvement in early graft function, long term kidney graft survival did not change significantly. ${ }^{5-7}$ The chronic allograft nephropathy (CAN) and the potential toxicity of cyclosporine had prompted the development of tacrolimus, a drug which has a similar mode of action to cyclosporine. Tacrolimus was first used in clinical transplantation in 1989. ${ }^{4}$ The studies produce some conflicting data regarding long term graft survival after use of cyclosporine or tacrolimus. Despite that the use of tacrolimus in kidney transplantation has considerably been increased.

Our aim of this study was to share our experience of the two CNIs at transplant unit of BIRDEM General Hospital.

\section{Methods}

This retrospective study was conducted in transplant unit of BIRDEM General Hospital. Data were collected in a preformed questionnaire from the hospital records with the permission from the Director General of the Institute. A total of 111 patients who had undergone live related donor kidney transplantation in BIRDEM from November 2004 to September 2014 were included in this study. They were divided into 2 groups, group 1 consisted of patients who received cyclosporine and group 2 consisted of those who received tacrolimus. We retrospectively evaluated patients' clinical and laboratory findings.

\section{Results}

Total patients were 111, 50 were in group I (who received cyclosporine) and 61 were in group 2 (who received tacrolimus). The base-line characteristics of the patients are given in table I. The immediate findings after transplantation were more in favor of patients on tacrolimus. The incidence of acute allograft rejection was significant ( $\mathrm{p}=0.014$ ) in group 1 and new onset of diabetes was significantly more $(p=0.025)$ in group 2 . During discharge from hospital after kidney transplantation, there was no significant difference in serum creatinine $(p=0.258)$ of these two groups but, mean time for normalization of serum creatinine $(p=0.001)$ and mean duration of hospital stay $(\mathrm{p}=0.005)$ were significantly less in group 2 (table II).

Tacrolimus use was started in our center as maintenance immunosuppressive in October 2009. So, data of five years' graft survival was not available for them. There was no significant change in graft survival at one-year $(p=0.308)$ and three-year $(p=0.441)$ between the two groups of patients (table III).

Table I

Base-line characteristics of patients on cyclosporin (group 1) and tacrolimus (group 2)

\begin{tabular}{lcc} 
Base-line characteristics & $\begin{array}{c}\text { Group 1 } \\
{[\mathrm{n}(\%)]}\end{array}$ & $\begin{array}{c}\text { Group } 2 \\
{[\mathrm{n}(\%)]}\end{array}$ \\
\hline Number of patients & 50 & 61 \\
Male & $33(66 \%)$ & $44(71.13 \%)$ \\
Female & $17(34 \%)$ & $17(27.87 \%)$ \\
Mean age (years) & $36.8 \pm 10.83$ & $38.22 \pm 10.36$ \\
Causes of ESKD & & \\
$\quad$ DM & $14(28 \%)$ & $17(27.87 \%)$ \\
$\quad$ CGN & $28(56 \%)$ & $25(40.98 \%)$ \\
$\quad$ HTN & $6(12 \%)$ & $19(31.15 \%)$ \\
Others & $2(4 \%)$ & $0(0 \%)$ \\
RRT prior to transplant & & \\
Pre-emptive & $2(4 \%)$ & $0(0 \%)$ \\
Haemodialysis & $46(92 \%)$ & $61(100 \%)$ \\
CAPD & $2(4 \%)$ & $0(0 \%)$ \\
\hline
\end{tabular}

[ESKD=end stage kidney disease; $\mathrm{DM}=$ diabetes mellitus; CGN=chronic glomerulonephritis; HTN=hypertension; $\mathrm{RRT}=$ renal replacement therapy; $\mathrm{CAPD}=$ continuous ambulatory peritoneal dialysis] 
Table II

\begin{tabular}{lccc}
\multicolumn{4}{c}{ Comparison of patients on cyclosporin (group 1) and tacrolimus (group 2) } \\
& Group 1 & Group 2 & p-value \\
\hline Mean time of normalization of s. creatinine (days) & $7.26 \pm 5.6$ & $4.71 \pm 2.3$ & 0.001 \\
No. of acute allograft rejection & 2 & 0 & 0.014 \\
Mean hospital stay (days) & $13.65 \pm 5.0$ & $11.38 \pm 3.33$ & 0.005 \\
Mean s. creatinine on discharge (mg/dl) & $1.42 \pm 0.91$ & $1.27 \pm 0.56$ & 0.258 \\
New onset of DM & $6(12 \%)$ & $18(29.5 \%)$ & 0.025 \\
\hline
\end{tabular}

Table III

Comparison of graft survival of patients on cyclosporin (group 1) and tacrolimus (group 2)

\begin{tabular}{lccc} 
& Group 1 & Group 2 & p-value \\
\hline 1 year graft survival (from Nov 2004 to September 2013) & 43 of 47 (92.0\%) & 52 of 54(96.2\%) & 0.308 \\
3 year graft survival (from Nov 2004 to September 2011) & 40 of 48 (83.3\%) & 33 of 37(89.2\%) & 0.441 \\
5 year graft survival (from Nov 2004 to September 2009) & 34 of 44(77.3\%) & - & - \\
\hline
\end{tabular}

\section{Discussion}

This retrospective study was performed in two groups of renal transplant recipients treated with cyclosporine or tacrolimus to evaluate graft function. In 1995, Gjertson et al. reported a significant improvement in long term renal graft survival for recipients of tacrolimus based immunosuppression evidenced by renal allograft half life of 13.8 years and 8.8 years in tacrolimus and cyclosporine based immunotherapy respectively. ${ }^{5}$ In 1998, Cecka JM et al. failed to confirm those early findings. Their results showed $90 \%$ one-year graft survival rate in patients on cyclosporine based immunosuppression, compared to $87 \%$ of tacrolimus based therapy. ${ }^{9}$ Till 1999, no randomized trial had shown an improvement in patient or renal graft survival at oneyear for patients receiving tacrolimus. ${ }^{10-12}$ Pirsch JD et al. found one-year graft survival rates were $91.2 \%$ for tacrolimus and $87.9 \%$ for cyclosporine. ${ }^{10}$ Mayer AD et al. in 1997 found no significant difference in tacrolimus vs cyclosporine based therapy at one-year (82.5\% vs. $86.2 \%)$ graft survival and (93.0\% vs. $96.5 \%)$ patient survival respectively) in their study on 448 renal transplant recipients ${ }^{11}$ and so as Vincenti $\mathrm{F}$ et al. ${ }^{12}$ in 1996.

The introduction of more potent immunosuppressive agents over decades has resulted in a progressive improvement in one-year graft survival rates after renal transplantation. While long-term graft survival has followed a similar trend, the number of functioning grafts continues to decline at an annual rate of 3-5\% after the ûrst year post-transplantation. ${ }^{13,14}$ Since tacrolimus immunosuppression in renal transplantation is associated with a lower incidence of acute rejection, a more favourable cardiovascular risk proûle and better renal function than cyclosporine, it was anticipated that tacrolimus may improve long-term kidney graft survival. ${ }^{15,16}$

As we have started using tacrolimus in October 2009, we could study upto three years graft survival between two groups of patients. As in others we also found that overall graft survival was almost similar at one-year and three-years between the groups. But the immediate posttransplant recovery period was more favorable in patients receiving tacrolimus. Acute allograft rejection was noted only in patients with cyclosporine. Incidence of new onset diabetes was significant among tacrolimus users.

The patient pool was not so large and there is still scope to assess further long-term graft survival of these patients.

One of the CNIs, cyclosporine, had started a new era in transplant medicine by dramatic improvement in early graft survival after its launch. Tacrolimus is getting it further ahead which is also evident in our study. 


\section{References}

1. Kalble T, Alcaraz A, Budde K, Humke U, Karam G, Lukan $\mathrm{M}$ et al. Immunosuppression After Kidney Transplant. European Association Urology (EAU) 2009; 55-65.

2. Halloran PF. Immunosuppressive Drugs for Kidney Transplantation. N Engl J Med 2004; 351: 2715-29.

3. Gaston RS. Current and Evolving Immunosuppressive Regimens in Kidney Transplantation. Am J Kidney Dis 2006; 47: S3-21.

4. National Kidney Foundation. Milestones in Organ Transplantation. 2013.

5. Gjertson DW, Cecka JM, Terasaki PI. The Relative Effects of FK506 and Cyclosporine on Short- and Long-term Kidney Graft Survival. Transplantation 1995; 60: 1384-88.

6. Starzl TE, Fung J, Venkataramman R, Todo S, Demetris AJ, Jain A. FK506 For Liver, Kidney and Pancreas Transplantation. Lancet 1989; 1000-4.

7. Knoll GA, Bell RC. Tacrolimus Versus Cyclosporin for Immunosuppression in Renal Transplantation: Meta-analysis of Randomised Trials. BMJ 1999; 318: 1104-7.

8. Shapiro R, Jordan M, Scantlebury V, Fung J, Jensen C, Tzakis A et al. FK506 in Clinical Kidney Transplantation. Transplant Proc 1991; 23: 3065-67.

9. Cecka JM. The UNOS Scientific Renal Transplant Registry. Ten Years of Kidney Transplants. In: Cecka JM, Terasaki PI, eds. Clinical transplants 1997. Los Angeles: Regents of the University of California, 1998.
10. Pirsch JD, Miller J, Deierhoi MH, Vincenti F, Filo RS. A Comparison of Tacrolimus (FK506) and Cyclosporine for Immunosuppression After Cadaveric Renal Transplantation. Transplantation 1997; 63: 977-83.

11. Mayer AD, Dmitrewski J, Squifflet JP, Besse T, Grabensee B, Klein B et al. Multicenter Randomized Trial Comparing Tacrolimus (FK506) and Cyclosporine In The Prevention of Renal Allograft Rejection. Transplantation 1997; 64: 436-43.

12. Vincenti F, Laskow DA, Neylan JF, Mendez R, Matas AJ. One-year Follow-up of an Open-label Trial of FK506 for Primary Kidney Transplantation. Transplantation 1996; 61: 1576-81.

13. Hariharan S, Johnson CP, Bresnahan BA, Taranto SE, McIntosh MJ, Stablein D. Improved Graft Survival After Renal Transplantation in the United States, 1988 to 1996. N Engl J Med 2000; 342: 605-12.

14. Pascual M, Theruvath T, Kawai T, Tolkoff-Rubin N, Cosimi AB. Strategies to Improve Long-term Outcomes After Renal Transplantation. N Engl J Med 2002; 346: 580-90.

15. Vincenti F, Jensik SC, Filo RS, Miller J, Pirsch J. A Longterm Comparison of Tacrolimus (FK506) and Cyclosporine in Kidney Transplantation: Evidence For Improved Allograft Survival at Five Years. Transplantation 2002; 73: 775-82.

16. Margreiter R. The European Tacrolimus vs Ciclosporin Microemulsion Renal Transplantation Study Group. Efficacy and Safety of Tacrolimus Compared with Ciclosporin Microemulsion in Renal Transplantation: A Randomised Multicentre Study. Lancet 2002; 359: 741-46. 